\title{
Currículo integrado, juventudes e espaços de participação
}

\author{
Integrated curriculum, youth and spaces for participation
}

\author{
Ana Cláudia Burmester (iD https://orcid.org/0000-0001-7237-1220 \\ Instituto Federal de Santa Catarina \\ E-mail: ana.burmester@ifsc.edu.br
}

Roberta Pasqualli (iD https://orcid.org/0000-0001-8293-033X

Instituto Federal de Santa Catarina

E-mail: roberta.pasqualli@ifsc.edu.br

\section{Resumo}

Esse artigo tem a finalidade de apresentar as discussões realizadas em uma oficina formativa sobre currículo integrado, juventudes e espaços de participação com jovens em uma perspectiva de criação de sentidos e significados, de participação e protagonismo juvenil frente aos saberes que perpassam a Educação Profissional e Tecnológica. De natureza aplicada, a pesquisa foi realizada a partir dos conceitos da pesquisa participante, de abordagem qualitativa, com estudantes de cursos Técnicos Integrados ao Ensino Médio no Instituto Federal de Santa Catarina. Como resultados, observa-se que o currículo integrado deve ser entendido enquanto uma proposta ético-política que demanda estratégias metodológicas que possibilitem a integração das suas dimensões, dos conhecimentos e dos seus sujeitos, com especial atenção às pluralidades das juventudes.

Palavras-chave: Currículo. Integração Curricular. Ensino Médio. Juventude.

\begin{abstract}
This article aims to present the discussions held in a training workshop on integrated curriculum, youth and spaces for participation with young people in a perspective of creating senses and meanings, of youth participation and protagonism in view of the knowledge that permeates Professional and Technological Education. Of an applied nature, the research was carried out from the concepts of participatory research with a qualitative approach, with students from Technical Courses Integrated into High School at the Federal Institute of Santa Catarina. As a result, it is observed that the integrated curriculum must be understood as an ethical-political proposal that calls for methodological strategies that enable the integration of its dimensions, knowledge and its subjects, with special attention to the pluralities of youth.
\end{abstract}

Keywords: Curriculum. curricular integration. Secondary Education. Youth.

\section{Introdução}

Esse artigo é resultante de uma parcela dos estudos realizados durante a elaboração da pesquisa intitulada Tempos e espaços para (re)pensar o currículo com estudantes do Ensino Médio Integrado, no Programa de Mestrado Profissional em Educação Profissional e Tecnológica (PROFEPT-IFSC), que se voltou à relação dos jovens com o currículo dos cursos de Ensino Médio Integrado (EMI), em uma perspectiva criadora 
de sentidos e significados, de participação e protagonismo juvenil frente aos saberes que perpassam a Educação Profissional e Tecnológica (EPT). Emerge de reflexões a respeito das especificidades do currículo desses cursos, bem como da condição de seus estudantes, compreendida a partir do conceito de juventudes.

Tal perspectiva apoia-se nas relações intrínsecas de constituição dos currículos e de seus sujeitos, conforme os pressupostos de Arroyo (2013), e é contextualizada a partir da concepção das identidades plurais dos jovens que são os sujeitos do EMI, nos termos discutidos por Carrano e Dayrell (2014).

Para além de compreender as identidades juvenis, o propósito é a busca por formas de integrá-las ao currículo a fim de que seja fomentada uma mudança de postura dos sujeitos com relação a ele e aos conhecimentos que dele fazem parte, o que caracteriza, na visão de Machado (2010), um movimento necessário à materialização do currículo integrado.

O problema de pesquisa destacado neste texto fundamenta-se no seguinte questionamento: como criar tempos e espaços que permitam aos jovens conhecer os currículos dos cursos de EMI para que possam neles se reconhecer e a eles dar sentido?

Buscando responder a esse problema, a pesquisa aplicada desenvolveu um produto educacional que, de acordo com Freire, Guerrini e Dutra (2016, p. 102) são "ferramentas pedagógicas, elaboradas pelos próprios profissionais em formação que comportam conhecimentos organizados objetivando viabilizar a prática pedagógica".

O produto educacional, caracterizado como uma oficina formativa sobre currículo integrado, juventudes e espaços de participação, projetou-se como uma estratégia metodológica para promover a participação dos estudantes em espaços de discussão a respeito do currículo integrado, visando à formação integral a partir do protagonismo discente e da criação de sentidos em relação ao currículo.

Este artigo discorre, na sequência, a respeito da proposição, do embasamento teóricometodológico e do desenvolvimento da oficina formativa aplicada no contexto da EPT.

\section{Panorama teórico quanto ao currículo integrado}

O currículo escolar envolve a seleção, não neutra, de conhecimentos historicamente produzidos pela humanidade, os quais precisam ser repassados às demais gerações. Contudo, ele não pode ser reduzido apenas ao aspecto instrumental de relacionar e hierarquizar conteúdos. O currículo representa e apresenta os sujeitos e suas identidades, valores e concepções de educação, de mundo, de trabalho, de mundo do trabalho. Embasadas em conteúdos, objetivos e práticas estão, portanto, concepções filosóficas, políticas e epistemológicas. Dessa forma, o currículo é concebido enquanto espaço de disputas e produção de identidades (Arroyo, 2013; Silva, 2015).

Assim, nas discussões acerca do currículo, não se pode perder de vista o seu caráter processual, isto é, a compreensão de que se trata de uma construção histórico-cultural humana, que serve às finalidades educativas, as quais, igualmente, constroem-se nas disputas e contradições que os sujeitos sociais vivenciam. Assumir essa concepção 
de currículo implica dar ênfase aos papéis que os sujeitos têm no seu processo de constituição.

Relacionando tal perspectiva ao contexto formativo do EMI, afirma-se que os objetivos dele dizem respeito à integração dos conhecimentos bem como à integração dos sujeitos ao processo pedagógico, por meio do reconhecimento de suas identidades e seus saberes. Conforme salienta Ramos (2010), os sentidos da formação do Ensino Médio, enquanto última etapa da educação básica, também em sua forma integrada à Educação Profissional Técnica de Nível Médio (EPTNM), voltam-se aos conhecimentos e aos seus sujeitos.

A ideia da integração, de acordo com Ciavatta (2012), remete-se ao objetivo de compreender a educação como uma totalidade social, tendo em vista o objetivo maior da emancipação humana. Desta forma, a preparação para o trabalho deveria estar articulada à educação geral.

Frigotto (2012), por sua vez, afirma que o currículo integrado possibilita o domínio de conhecimentos em duas esferas, quais sejam a sociedade humana e suas relações e o mundo natural e, a partir desse domínio, o estudante constitui-se para a emancipação e a criticidade, compreendendo que pode agir sobre a realidade e transformá-la, incluindo-se nela os sistemas produtivos e os conhecimentos técnicocientíficos a eles relacionados.

É possível afirmar que o currículo integrado da EPTNM se assenta, teórica e filosoficamente, sobre bases socialistas, mesmo que não se confunda com a perspectiva da formação omnilateral ou politécnica de Marx, nem a escola unitária de Gramsci, uma vez que aquelas não se refeririam à profissionalização para adolescentes e jovens, conforme explicam Moura, Lima Filho e Silva (2015). No entanto, os autores também salientam que é necessário compreender o contexto da sociedade contemporânea a fim de pensar os projetos formativos para esses sujeitos.

Nesse aspecto, mostra-se bastante interessante a reflexão proposta por Pinto (2005), que retoma o lugar da técnica em relação direta com o trabalho humano e não afastada dos sujeitos, como se fosse uma entidade abstrata. Para ele, a técnica igualmente caracteriza um processo de emancipação do trabalhador, somente existindo a partir do ser humano e de sua intervenção consciente na natureza e na realidade material. Por isso, defende-se aqui a compreensão da técnica enquanto uma dimensão constituinte da formação integral dos sujeitos, assim como os conhecimentos técnico-profissionais que fazem parte do currículo integrado da EPTNM.

Por isso, vale reafirmar que o projeto do currículo integrado apreende o trabalho como princípio educativo e contexto formativo, mas sem perder o horizonte da emancipação humana. Conforme explica Ramos (2008), o EMI, sob uma base unitária, representa uma defesa ético-política da formação dos jovens que, enquanto profissionais com uma sólida formação geral, poderão enfrentar as adversidades da realidade material e dos sistemas produtivos e econômicos atuais. Além disso, serão habilitados para o exercício crítico dessas profissões, mas sem nunca se esgotar a elas.

\section{Integração das identidades juvenis ao currículo}

A integração dos conhecimentos representa a compreensão de que os conteúdos de ensino, presentes no currículo formal, não têm fins em si mesmos, mas servem ao 
propósito maior de promover a compreensão dos fenômenos reais, a partir do esforço dialético de analisar além das suas aparências (Ramos, 2008).

$\mathrm{Na}$ formação da EPTNM, os fenômenos dizem respeito às dimensões da vida humana, que incluem as relações de trabalho e os sistemas de produção, em suas formas historicamente constituídas. Por isso, Ramos (2014) sugere pensar a organização do currículo integrado levando em consideração as múltiplas dimensões que constituem os sistemas produtivos e as áreas profissionais, tecendo relações entre conceitos, conhecimentos e teorias para proporcionar análises problematizadoras dos fenômenos do mundo do trabalho. Tais relações poderiam gerar sentidos que demonstrem a integração dos conhecimentos e a articulação das dimensões humanas da vida. $\mathrm{E}$ a partir de tal concepção se afirma que o currículo integrado precisa incluir as discussões acerca das identidades dos seus sujeitos e dos sentidos que são construídos por eles em meio à formação escolar e profissional.

A integração, nesse contexto, é apresentada por Machado (2010) sob dois aspectos. O primeiro refere-se ao entendimento do estudante enquanto um sujeito que vivencia outros papéis na sociedade e portanto, sua vida, assim como concebido no currículo integrado, é composta por diferentes dimensões. O segundo aspecto é que, para que o currículo seja significativo, deve ser "integrado à vida dos educandos, à dinâmica da interação e dos processos históricos, sociais, econômicos e culturais relevantes que estes vivenciam" (Machado, 2010, p. 82).

A integração dos sujeitos ao contexto formativo pode ser relacionada à função social que a escola desempenha bem como aos sentidos que são desenvolvidos, pelos jovens, em relação à experiência escolar. Essa noção acerca dos sentidos é apresentada por Dayrell (2007) e é abordada por outros pesquisadores, a exemplo de Gusmão (2016); Batista (2007) e Bernardim e Silva (2016).

No que se refere à EPT e ao currículo integrado, essa produção de sentidos também perpassa as relações dos jovens com a escola e o mundo do trabalho, representando um grande desafio para a integração de sujeitos e conhecimentos. Para Machado (2010), a materialização do currículo integrado exige a contextualização sociocultural do processo de ensino-aprendizagem, trazendo para as práticas educativas os estudantes e seus interesses, suas necessidades e demandas, e desenvolvendo a compreensão da realidade vivida por eles a partir de diferentes dimensões.

Nesse sentido é que não se pode perder de vista a complexidade da constituição identitária dos jovens nem se deve relacionar a condição juvenil apenas ao papel de aluno, sob risco de diminuir a voz e a presença dos jovens em sociedade e nos espaços institucionais. Para além do entendimento biopsicológico, é preciso compreendê-la a partir do desejo de desenvolver uma identidade singular, em meio à relação com os outros e ao contexto vivido. Por isso, é sempre importante reafirmar a condição juvenil enquanto uma construção cultural e social, concepção teórica defendida por Dayrell (2007); Carrano e Dayrell (2014); Arroyo (2014) e Leccardi (2005).

Para tentar dar conta de tal complexidade que é refletida diretamente no currículo escolar, Carrano e Dayrell (2014) sugerem adotar a concepção de juventudes plurais a qual, no entanto, não apaga as singularidades das identidades individuais dos jovens. Tomar as juventudes enquanto uma categoria de análise e de proposição de ações pedagógicas e políticas educacionais não objetiva, portanto, homogeneizar as identidades dos sujeitos mas, pelo contrário, significa compreender que é necessário ultrapassar definições pré-concebidas a respeito do que é ser jovem. 
Arroyo (2014) igualmente se utiliza da proposta de analisar as imagens que são construídas sobre os jovens e sobre os alunos constatando, inevitavelmente, que elas se quebram e, mais do que isso, precisam se quebrar. Afinal, se os sujeitos são outros, porque constantemente estão se construindo social e culturalmente, a escola e o currículo podem permanecer indiferentes às novas identidades? Para a integração curricular, a resposta claramente é negativa.

Retomando os pressupostos da formação integrada, Ciavatta (2012) destaca a relevância das discussões coletivas quanto a estratégias acadêmico-científicas de integração, além da articulação com alunos e suas famílias acerca da experiência da formação integrada, as expectativas e as suas possibilidades de concretização. O processo de dar voz aos estudantes e promover a sua participação e seu protagonismo diante da compreensão e construção do currículo mostra-se como possibilidade formativa, ao mesmo tempo em que representa desafios às práticas pedagógicas.

Os desafios relacionam-se, conforme pontua Arroyo (2014), à própria instituição escolar que pouco incentiva a verdadeira participação estudantil. Tal processo de gestão escolar democrática e participativa, por vezes ainda frágil em muitos contextos, pode estar atrelado às relações hierárquicas entre os sujeitos da escola, às visões pré-concebidas sobre os estudantes, bem como aos sentidos que eles desenvolvem a respeito da formação escolar.

As visões estereotipadas e preconceituosas sobre os jovens e suas possibilidades de organização e participação relacionam-se diretamente à estrutura hierárquica característica do sistema escolar, que gera relações desiguais de poder. Martins e Dayrell (2013) associam essa desigualdade ao conflito intergeracional, a partir do qual os adultos enxergam, nos jovens, apenas imaturidade e, dessa forma, desconsideram-nos como sujeitos sociais. Zibas, Ferretti e Tartuce (2006), por sua vez, voltam a análise para a insegurança de docentes e gestores de terem sua autoridade questionada pelos estudantes, caso eles se organizem para participar, individual ou coletivamente.

Promover a participação dos estudantes demanda, portanto, a consciência dos sujeitos quanto às relações hierárquicas, no sentido de não as naturalizar, mas compreender a sua existência de tal forma que o protagonismo estudantil não se confunda com a responsabilização individual dos estudantes pela falta ou superficialidade de participação. Enfim, não se pode desconsiderar que os sujeitos possuem papéis diferentes no contexto escolar, e que também cabe à escola possibilitar experiências de aprendizado e vivência do processo democrático.

Compreende-se, portanto, que participar é um processo, o qual precisa ser aprendido e ensinado. Conforme explicam Carrano e Dayrell (2014), a participação implica a formação teórica para a vida cidadã e a criação de tempos e espaços para a vivência do exercício democrático.

Pensar na formação que objetiva integrar sujeitos e conhecimentos em suas múltiplas dimensões, mediados pelo processo do trabalho, em seu sentido ontológico, representa um exercício pedagógico e político de promoção da autonomia e liberdade dos sujeitos, por isso relaciona-se ao exercício da democracia, conforme também aponta Ciavatta (2012).

Para Arroyo (2013), o diálogo participativo possibilita que a escola e o currículo se voltem para outras dimensões formativas, que dizem respeito diretamente às vidas 
dos estudantes. Trata-se do direito ao saber de si e de seus direitos, em meio aos conhecimentos que possibilitam analisar fenômenos a partir de dimensões sociais, políticas e econômicas.

Os jovens que participam do currículo integrado precisam compreender os sentidos da integração em suas próprias vidas, nas dimensões da cultura, do trabalho, da ciência e da tecnologia. Para isso, perceber-se como sujeitos ativos do processo formativo, que produzem conhecimentos e são ouvidos, representa uma vivência política e pedagógica para a formação integral.

Compreendida a base teórica, na sequência do artigo apresenta-se o processo metodológico que deu suporte para o desenvolvimento da pesquisa.

\section{Procedimentos Metodológicos}

De natureza aplicada, a pesquisa foi realizada a partir dos conceitos da pesquisa participante, de abordagem qualitativa, em um universo de 71 sujeitos, sendo 34 estudantes vinculados ao curso de Técnico em Alimentos Integrado ao Ensino Médio e 37 estudantes vinculados ao curso de Edificações Integrado ao Ensino Médio. Deste universo, foram 39 os que aceitaram o convite e responderam ao questionário utilizado para a coleta de dados e tornando-se a amostra da pesquisa. Dos 39 estudantes, 19 eram do curso de Alimentos (AL) e 20 do curso de Edificações (ED) Integrado ao Ensino Médio do Instituto Federal de Educação, Ciência e Tecnologia de Santa Catarina (IFSC) Campus Canoinhas, região do planalto norte catarinense.

Os sujeitos da pesquisa contemplaram estudantes do sexto módulo desses cursos, cujas turmas foram as primeiras a serem ofertadas pelo campus. A escolha por esse público deu-se em virtude de sua representatividade no que se refere ao processo de implantação do currículo integrado no campus. Esses jovens representam os primeiros estudantes dos primeiros cursos integrados ofertados pelo IFSC Campus Canoinhas.

Dos 39 participantes, 20 possuíam 17 anos e 19 possuíam 18 anos. Todos haviam concluído o ensino fundamental na rede pública. A maioria, ou seja, 35 participantes residiam no mesmo município em que se encontra o campus, mas havia 4 estudantes que residiam em dois municípios vizinhos, distantes cerca de $20 \mathrm{~km}$ da instituição. Dentre aqueles que residiam no mesmo município, também se observou que existiam moradores de zona rural. Do público pesquisado, 23 não exerciam atividade remunerada e 3 afirmaram que não contribuíam com a renda familiar. Havia também 2 estudantes que realizavam estágio, 4 recebiam bolsas de pesquisa e 10 recebiam bolsa de extensão e 1 estudante que indicou realizar outro tipo de atividade remunerada, excluído trabalho com carteira assinada e contrato de jovem aprendiz.

A metodologia foi inspirada nas etapas atribuídas à pesquisa participante por Le Boterf (1987). A primeira fase abrangeu o delineamento teórico-metodológico, enquanto a segunda, que englobou o conhecimento da realidade que se propunha investigar, pressupôs o levantamento de dados junto aos participantes da pesquisa. A coleta de dados foi realizada por meio de questionário com perguntas abertas, utilizando-se a ferramenta Formulários do Google. Antes de sua aplicação, o instrumento foi analisado por quatro estudantes pertencentes à população da pesquisa, os quais foram convidados e se disponibilizaram para realizar a análise, dando suas 
contribuições a respeito das perguntas. O momento da aplicação do questionário foi organizado com os coordenadores dos cursos pesquisados e realizado nos laboratórios de informática do campus, no mês de agosto de 2018.

O instrumento foi organizado a partir de três seções. A primeira, intitulada 'quem é você?', continha seis perguntas de múltipla escolha e seis perguntas abertas que objetivaram delinear um perfil dos participantes e suas percepções a respeito da vivência da juventude e da formação no IFSC. A segunda parte, 'como é o curso que você faz?', contou com outras seis questões abertas a respeito da experiência formativa no curso técnico integrado. Finalmente, em 'qual é a sua participação?', os estudantes foram convidados a responder a mais seis perguntas abertas sobre os espaços e oportunidades de participação que vivenciam no IFSC.

Após a coleta, trabalhou-se com a análise de conteúdo conforme os estudos de Gomes (2007). As categorias de análise e os núcleos de sentido foram construídos dentro de três eixos temáticos, quais sejam: (a) jovens, estudantes e suas juventudes; (b) percepções quanto à formação integrada e, (c) sentidos construídos pelos jovens acerca dos processos participativos.

O terceiro momento da pesquisa foi organizado a partir da análise dos dados coletados, os quais também foram levados ao conhecimento da população da pesquisa. Esta etapa caracterizou, portanto, o desenvolvimento e a aplicação do produto educacional. Seguindo-se a ideia de Le Boterf (1987), que sugere o trabalho com grupos ou círculos de estudo, realizou-se uma oficina formativa, para a qual foram convidados os 39 estudantes que responderam ao questionário. O propósito desta etapa foi possibilitar aos estudantes conhecer e discutir o currículo de seus cursos e os espaços de participação existentes na instituição, repensando-os, caso assim indicassem ser necessário. A oficina foi tomada como uma possibilidade de prática pedagógica que buscou colaborar para a formação integral e a materialização do currículo integrado, a partir da perspectiva dos jovens estudantes que dele fazem parte. Desta etapa participaram 10 estudantes do público de pesquisa que foram selecionados em virtude do interesse individual de participação (Quadro 1).

Quadro 1 - Sujeitos da pesquisa

\begin{tabular}{|l|c|}
\hline População total da pesquisa que responderam ao questionário & 39 \\
\hline $\begin{array}{l}\text { Participantes da oficina formativa e que também responderam ao } \\
\text { questionário }\end{array}$ & 10 \\
\hline Perfil etário da população de pesquisa & 17 a 18 anos \\
\hline Residentes no mesmo município do campus & 35 \\
\hline Residentes em outros municípios & 4 \\
\hline Não exercem atividade remunerada & 23 \\
\hline Atividade de extensão remunerada & 10 \\
\hline
\end{tabular}




\begin{tabular}{|l|c|}
\hline Atividade de pesquisa remunerada & 4 \\
\hline Atividade de estágio remunerado & 2 \\
\hline Outra atividade remunerada & 1 \\
\hline Não contribui com a renda familiar & 36 \\
\hline Contribui com a renda familiar & 3 \\
\hline
\end{tabular}

Fonte: Burmester (2018, p. 32-33).

As falas apresentadas na sequência do texto em tela são oriundas dos diálogos realizados durante a realização da roda de conversa, que foi gravada para registro e transcrição. As falas foram denominadas como 'Roda de Conversa', já que se entende que, para as discussões apresentadas neste texto, interessam as generalidades e não as especificidades.

Finalmente, a etapa à qual Le Boterf (1987) denomina de plano de ação, correspondendo à quarta fase da pesquisa, culminou com o processo de avaliação dos participantes, desencadeado ao final da oficina formativa, por meio da sistematização das discussões e reflexões proporcionadas pela atividade.

É na direção de dar materialidade à terceira e quarta etapas da pesquisa realizada que a sequência deste texto versa.

O projeto de pesquisa foi submetido a Comitê de Ética em Pesquisa e aprovado, conforme parecer número 2.674.257, seguindo os procedimentos indicados pela Plataforma Brasil.

\section{Resultados e Discussões}

A concepção da oficina formativa sobre juventudes, currículo integrado e espaços de participação baseou-se na estratégia desenvolvida por Anastasiou (2004) e nos trabalhos de Silva (2014). Projetou-se como uma estratégia metodológica para promover a participação dos estudantes em espaços de discussão a respeito do currículo integrado, em uma perspectiva de protagonismo dos jovens e criação de sentidos e identidades com relação a esse currículo e ao objetivo da integração de conhecimentos e sujeitos, visando à formação integral.

Além disso, buscou qualificar a participação dos jovens nos espaços de decisão, não no sentido de considerar suas opiniões desprovidas de qualificação ou maturidade, mas na perspectiva de empoderamento e protagonismo dos estudantes.

A organização da oficina formativa contemplou os seguintes elementos: (a) contextualização acerca da atividade e seus propósitos, tendo em vista os objetivos e temas da pesquisa; (b) Contextualização histórica quanto ao currículo integrado no Brasil; (c) discussão sobre a natureza e os objetivos do currículo integrado e as dimensões que o compõem - trabalho, enquanto princípio educativo; ciência, 
tecnologia e cultura, ilustrando o seu horizonte formativo e o ideal de superar a fragmentação dos conhecimentos e das vidas dos sujeitos; (d) utilização de dados coletados por meio da aplicação do questionário, destacando os sentidos apontados pelos jovens quanto à experiência escolar e as formas de identificação deles em relação ao currículo integrado, para subsidiar as discussões; (e) considerações quanto aos espaços institucionais de participação estudantil, a partir dos referenciais do currículo integrado e das identidades juvenis, analisados com os estudantes e, (f) sistematização de encaminhamentos sugeridos pelos estudantes sobre a oficina e os espaços institucionais de participação estudantil.

A fim de promover as contextualizações necessárias para subsidiar as discussões e reflexões, as pesquisadoras escolheram vídeos, trechos de músicas, dados estatísticos a respeito das ofertas de cursos integrados e excertos de documentos institucionais.

Os dados levantados durante a pesquisa também serviram de elementos de (auto)reflexão e conduziram as discussões, objetivando proporcionar aos jovens reconhecer-se em meio a elas. Dessa maneira, compreende-se que as identidades, demandas e opiniões deles subsidiaram o trabalho reflexivo.

A estratégia metodológica empregada para a organização das atividades da oficina fundamentou-se na proposta das rodas de conversa. Para Warschauer (2004), a técnica da roda de conversa tem raízes em trabalhos comunitários e iniciativas coletivas de participação. Contudo, ela se faz pouco presente na educação formal, em virtude de perspectivas de "homogeneização, padronização e organização de espaços, tempos e currículos, estruturados de tal maneira a deixar poucas oportunidades para a manifestação das diferenças e singularidades" (Warschauer, 2004, p. 3). Por isso, Moura e Lima (2014) explicam que esse é um instrumento de pesquisa que promove a participação e o diálogo, além de fomentar o espaço de escuta do outro.

O espaço de formação foi planejado para uma duração aproximada de três horas e realizou-se durante a Semana Nacional de Ciência e Tecnologia (SNCT), evento tradicional realizado na Rede Federal de Educação Profissional e Tecnológica, e que havia sido apontado pelos estudantes, no questionário, como atividade significativa no contexto da sua formação escolar.

Por meio dos materiais e estratégias utilizados, foi possível desenvolver discussões a respeito da integração curricular, tendo em mente tanto os diferentes conhecimentos que devem fazer parte do projeto pedagógico no currículo integrado, quanto as próprias vivências e os diferentes papéis sociais que os jovens vivenciam. Assim, os estudantes abordaram as possibilidades de encontros de saberes vivenciados nos cursos:

Porque eu acho que são coisas que se estruturam, sabe? Quando você tem contato com aquilo, de ambos os lugares... de lugares diferentes, matérias diferentes, acaba construindo no teu cérebro, né? Você acaba raciocinando e puxando uma linha daqui uma linha dali. Você começa a completar as coisas e aquilo ali se torna muito fácil e prático (Roda de Conversa, 2018).

Nesse sentido, cabe ressaltar que os jovens destacaram esforços por parte de alguns professores, especialmente das unidades curriculares identificadas por eles como 
Ensino Médio (matemática, física, biologia, filosofia, etc.), para mostrar a relação entre as áreas, conforme se percebe na seguinte fala: "Até os professores do ensino médio mesmo.... Eles associam, eles dão exemplos ligados ao curso. Então, tipo, tem essa associação. Em todas as áreas" (Roda de Conversa, 2018).

Para a discussão acerca da integração curricular, também foi abordado o conceito apresentado por Ciavatta (2012) quanto a integrar, tornar-se inteiro, completo. $\mathrm{Na}$ sequência, os jovens reforçaram o entendimento de que é necessário um "balanço", numa ideia de equilíbrio na formação, pois consideram que é dada uma ênfase maior à formação técnica: "do ensino médio [os professores] sempre voltam pro curso... sempre falam do curso... do técnico... Nunca falam do ensino médio" (Roda de Conversa, 2018).

É importante destacar que as falas trouxeram essa divisão entre as áreas, referindose aos componentes curriculares da formação geral como "ensino médio" e os componentes próprios à atuação técnica como "o curso".

Uma ênfase foi dada, pelos jovens, à ideia da integração por meio do relacionamento interpessoal: "integrar é juntar, pra mim.... Integrar é isso. É todo mundo junto, pensando junto que vai fluir melhor" (Roda de Conversa, 2018). Essa concepção também poderia ser associada àquelas que envolvem a cultura, dimensão do currículo integrado, e que são relacionadas, pelos jovens, ao respeito às pessoas e suas culturas. Quando questionados acerca da importância das vivências durante a formação, os primeiros comentários direcionaram-se para a compreensão e o respeito às diferentes culturas:

Eu acho que nessas vezes que a gente tem a relação cultural no IFSC, a gente aprende muito mais que em sala de aula tendo uma disciplina chamada "relações humanas", eu preferiria muito mais estar lá, tendo que trocar ideia sobre o que é cultura, representando, seja lá... dentro de uma apresentação cultural você tem que ter uma relação boa com as pessoas que vão se relacionar com você. $E$, a gente acaba desenvolvendo uma relação melhor com as pessoas (Roda de Conversa, 2018).

A relação entre a cultura e a formação profissional também foi abordada em meio à discussão acerca das dimensões do currículo integrado: trabalho, ciência, cultura e tecnologia. Para um dos jovens, representa uma outra realidade para o estudante e para o trabalhador: "a gente é muito... estudar, estudar, estudar, estudar. Aí você pensa em show de talentos, música, ciência e tecnologia... é um outro mundo, sabe?" (Roda de Conversa, 2018).

É possível inferir que esse entendimento acerca da dimensão cultural bem como da integração relacionada às pessoas não se afasta da noção que se sustenta sobre a não fragmentação de conhecimentos. Por isso, quando os jovens comentam que enxergam seus cursos afastados dos demais cursos da instituição, como "se não fossem cursos técnicos" (Roda de Conversa, 2018), ou quando afirmam que não sabem do que se tratam os conhecimentos que são construídos e compartilhados pelos demais cursos da instituição, é possível afirmar que estão apontando a fragmentação do conhecimento. Ao mesmo tempo, quando chamam a atenção para as experiências que possibilitaram conhecer outras pessoas, por meio de projetos e atividades diversificadas, mas muitas vezes tidos como extracurriculares, ou mesmo a partir do relacionamento amigável com docentes e servidores administrativos, eles 
abordam a interação com as pessoas. No entanto acredita-se que também apontam a aproximação e a construção de conhecimentos que é possibilitada a partir dessa interação.

A roda de conversa ainda possibilitou discutir sobre as motivações para fazer um curso técnico integrado. Os jovens reforçaram a ideia da preparação para a vida, ao mesmo tempo em que enxergam a possibilidade da inserção no mundo do trabalho, mesmo em casos nos quais dizem não desejar seguir na área técnica por falta de identificação com ela. Conforme um dos participantes da roda de conversa: "a questão não só do estudo em si, mas você pode pensar e chamar um professor para escrever um projeto com você... em que lugar você teria essa oportunidade? Se você escolher um professor e ele ouvir o que você tem a dizer?" (Roda de Conversa, 2018).

No entanto, a discussão também se encaminhou para uma constatação de que, por vezes, os próprios professores restringem a visão das possibilidades que o curso integrado pode proporcionar. Segundo os jovens, isso ocorre porque os professores apresentam as suas escolhas profissionais como as únicas possíveis para quem se insere em determinada área técnica. Diante dessa constatação, os estudantes analisaram a importância de componentes curriculares e da postura de outros professores que buscam mostrar possibilidades diversas de inserção e atuação profissional. Um dos jovens explicou, por exemplo, que buscou, por conta própria, conhecer o projeto pedagógico de um curso de tecnologia a fim de visualizar de que maneira a sua formação técnica estaria relacionada a ele, indicando novas possibilidades futuras.

Compreendeu-se, ainda, que os sentidos da integração se constroem de formas variadas e dependem também das expectativas dos jovens a esse respeito, bem como de elementos que compõem as suas identidades plurais, assim como postulam Carrano e Dayrell (2014). Assim, observaram-se entendimentos acerca do EMI relacionados à possibilidade de inserção no mundo do trabalho ou de continuidade de estudos em áreas correlatas, ao mesmo tempo em que se manifestaram quanto à ampliação de horizontes proporcionada pela formação integrada. Algumas experiências vivenciadas durante o curso ganham destaque nas falas dos jovens, muitas vezes relacionadas a oportunidades de construção e troca de conhecimentos, de interação com outras pessoas, além de impactos na constituição da sua própria identidade.

O espaço formativo também possibilitou o compartilhamento de dificuldades vivenciadas pelos jovens com relação ao curso e, especificamente, à carga horária elevada. Os jovens complementaram, relatando o seu cansaço e o cansaço dos colegas. Afirmaram que é comum dormirem na sala de aula devido ao cansaço, ou mesmo faltarem às aulas. A rotina das atividades do curso, às quais adicionam-se atividades extracurriculares e, para alguns, trabalho, foi ilustrada pelo jovem: "semana passada eu nem vi os meus pais, eu saía de manhã e chegava de noite... eles tavam deitados, eu não via eles" (Roda de Conversa, 2018).

Nesse sentido, os estudantes revelaram que, no último ano, muitos colegas buscaram o apoio do psicólogo do campus, devido às pressões. As falas durante a roda de conversa também evidenciaram aspectos relativos ao relacionamento familiar desses jovens, que parecem indicar que as famílias não compreendem as suas experiências escolares: "eles [os pais] pensam que é como se a gente tivesse no fundamental ainda. É uma diversão ainda. [...] Aí, você chega em casa e tem que fingir que tá tudo bem, né? 'Como é que foi o dia?' Ótimo, maravilhoso" (Roda de Conversa, 2018). 
Não apenas proveniente da família, a falta de compreensão relacionada às dificuldades experimentadas por eles também foi aludida aos docentes: "quando os professores olham pra gente e fala... nossa, você só tem que estudar! E pra gente é tudo isso que tá rolando" (Roda de Conversa, 2018).

Ao abordar a dimensão da tecnologia no currículo integrado, foi possível instigar a discussão acerca dos usos que são feitos para os recursos tecnológicos, além de possibilitar ampliar a visão da tecnologia para além das máquinas e dos equipamentos. Nesse sentido, os jovens observaram que a tecnologia abrange "até o modo como você desenvolve as coisas de um jeito mais produtivo, sabe? Não necessariamente é uma máquina" (Roda de Conversa, 2018). Essa noção da tecnologia direcionada para o currículo integrado possibilitou o relato de situações que demonstram riscos associados à tecnologia e que, por isso, demandam atenção por parte daqueles que a utilizam, como os próprios estudantes.

O grupo de jovens comentou sobre um incidente durante uma atividade de laboratório e que poderia ter gerado consequências graves. Também demonstraram que ocorrem discussões acerca dos usos das tecnologias no contexto profissional, porém mais relacionadas aos componentes curriculares identificados pelos estudantes como sendo da área técnica: "tem caminhos pra você resolver, pra você construir... mas, você vai ver que aquele mais eficiente é o que não prejudica tanto o trabalhador, pra ele fazer menos esforço" (Roda de Conversa, 2018).

A partir dos materiais que embasaram a atividade, instigaram-se falas acerca da experimentação e da relação indispensável entre teoria e prática para a produção da ciência, as quais incentivaram os jovens a também refletir sobre o processo de construção de conhecimentos em seus cursos o que, por sua vez, depende dos estudos de caráter mais teórico tanto quanto das vivências práticas, enquanto fenômenos complementares:

\begin{abstract}
Daí que a gente vê a importância da prática, né? Porque coloca na prática o que realmente você aprendeu, né? Então, você fazer o PI [Projeto Integrador], assim.... vamos colocar o exemplo o $\mathrm{PI}$, mas, se você não tem um conhecimento sobre aquilo... se você não tem na teoria... você não sabe colocar ali... até a questão de ir na prática na questão da obra mesmo. [...] Se aconteceu um erro, você vai lá e estuda... pra consertar e ficar certo [...]. Porque em matérias teóricas, por exemplo... a gente tem o projeto elétrico... a gente tinha uma dúvida enorme em um certo tipo de corrente elétrica... nós vamos dar hoje uma oficina pro pessoal sobre [...] elétrica. Aí, a gente fazendo na prática a gente conseguiu entender que uma coisa na teoria a gente não tinha conseguido (Roda de Conversa, 2018).
\end{abstract}

Finalmente, a partir da letra de uma música que sugere uma distinção entre os conceitos de trabalho e emprego, foi promovida uma reflexão junto aos jovens a respeito da noção de trabalho envolvida nos cursos integrados. Para os estudantes, de forma geral, "parece que quem diz que tem um trabalho já fala com mais vontade, assim.... parece que eles têm gosto com o que estão fazendo. [...] Eles têm dimensão daquilo, né?" (Roda de Conversa, 2018).

As ideias relativas aos papéis diferentes vivenciados pelos sujeitos também foram relacionadas ao conceito de trabalho, buscando-se destacar, nesse sentido, os objetivos da formação integrada e ampla para aqueles que, entre tantas outras funções sociais, também são trabalhadores: 


\begin{abstract}
Eu acho que a hora que você chega e pergunta: o que você é? A pessoa se define pela profissão e não pelo que realmente ela é. Ah, você é engenheiro, eu sou médico. Tá, mas além disso? O que você é? Eu sou pai, eu sou filho, eu sou mulher, eu sou esposa... eu sou namorada... ou então, eu sou a pessoa que adora apreciar comida típica... ouvir música à noite.... Que gosta de assistir séries.... Ficar com a família. Tipo, a sociedade impõe que a partir do momento que você escolhe uma profissão você é aquilo. Mas, você tem seu lado pessoal.... Muito além daquilo, né? (Roda de Conversa, 2018).
\end{abstract}

Dessa maneira, procurou-se relacionar as dimensões a partir da noção diferenciada de trabalho que embasa o currículo integrado e que se trata de seu princípio pedagógico, propondo que se pensasse a integração em meio a essas relações e que, talvez dessa maneira, os sujeitos também pudessem se sentir integrados ao currículo. Foi destacada a compreensão do currículo enquanto construção social e histórica e a integração, um horizonte a ser almejado. E nesse sentido, pode também ser relacionada a participação dos jovens nos espaços institucionais de decisão como parte da formação integrada.

Refletindo sobre os espaços institucionais de participação coletiva, os jovens compartilharam relatos a respeito de dificuldades que tiveram e que, em sua opinião, são comuns aos demais estudantes e por isso demandam atenção. Salientaram a necessidade de espaços para troca de experiências entre eles próprios: estudantes conversando com outros estudantes. Propuseram, inclusive, oportunidades para que pudessem dialogar com futuros estudantes dos cursos EMI, a fim de compartilhar suas experiências e o entendimento acerca desses cursos: "pedir pra que os alunos façam isso como uma conversa, assim.... eu acho que a gente devia falar com o primeiro ano... porque, ah... fiquei tão decepcionada com meu primeiro ano..." (Roda de Conversa, 2018).

Assim, ressaltaram a importância de espaços formativos que, na opinião deles, deveriam ser pensados em ciclos. Eles perceberam que foi o tempo de curso e de experiência na instituição que auxiliou no desenvolvimento de uma maturidade para opinar sobre certas questões, a exemplo dos exercícios reflexivos propostos na oficina.

No momento da sistematização das ideias, os jovens explicaram que os temas abordados no espaço formativo foram ao encontro de discussões que eles próprios já vinham desenvolvendo. Além disso, indicaram que o espaço possibilitou a compreensão acerca das ideias de integração, ciência, cultura e tecnologia presentes no Projeto Pedagógico de Curso (PPC) dos cursos, sobre as quais não tinham conhecimento anterior: "vamos ser bem claras... ninguém leu o PPC. Deveria ter uma oficina sobre isso, né? Já mostrando a integração assim... não sei vocês, mas eu só soube hoje..." (Roda de Conversa, 2018). Identificaram, ainda, que "apresentar o PPC de forma dinâmica ajuda a compreender melhor os objetivos do IF [Instituto Federal]" (Roda de Conversa, 2018). Para o grupo, o espaço organizado como uma roda de conversa se mostrou "aberto e confortável para os estudantes proporem novas formas de abordar a integração, com base nas experiências vividas" (Roda de Conversa, 2018).

No que se refere aos espaços participativos, os jovens apontaram os conselhos de classe como importantes momentos, mas reforçaram o seu indispensável caráter participativo: "conselhos participativos com a participação de professores [risos]... com 
todos os professores presentes" (Roda de Conversa, 2018). Explicaram que, por vezes, por esses momentos ocorrerem em horários de aula, nem todos os docentes os acompanham. Além disso, enfatizaram a necessidade de se compreenderem as críticas construtivas trazidas pelos estudantes.

O grupo também reforçou a necessidade da participação dos estudantes na escrita dos PPC: "uma coisa que a gente pediu e até agora não foi trazido nenhum retorno é sobre a gente opinar no PPC do curso" (Roda de Conversa, 2018).

Ainda no que se refere aos espaços coletivos, apontaram a necessidade de reorganização de momentos de divulgação de trabalhos e projetos desenvolvidos pelos colegas. Analisando exemplos de eventos como seminários de Ensino, Pesquisa, Extensão e Inovação, os jovens defenderam uma maior e melhor divulgação para a comunidade acadêmica das diferentes ações de pesquisa, extensão, cultura, ciência e tecnologia nas quais podem se envolver enquanto participantes do EMI. Assim, a proposta do grupo foi apresentada no sentido de que ocorresse a divulgação dessas oportunidades a todos os jovens estudantes, e não apenas um compartilhamento daquilo que já foi desenvolvido por alunos e servidores.

\begin{abstract}
Nossa, eu pensava: mais projeto pra fazer.... Mas, hoje a gente vê a importância que é, né? Tipo, o quanto abre portas pra gente... não só pro currículo, mas por vivências que a gente tem... não participar só por bolsa, mas pô... voluntário também... você vai ter uma coisa a mais no seu currículo... você vai se envolver com coisas diferentes... Eu acho que era importante eles terem essa reflexão...Tem gente que não gosta do curso... mas, muita gente pensa: eu não gosto, mas o que isso vai trazer pra mim? Esses ensinamentos que eu tô tendo agora... vai trazer ensinamentos pra mim? Eu vou levar pra uma área da minha vida, talvez? (Roda de Conversa, 2018).
\end{abstract}

Considera-se que as análises desenvolvidas pelos jovens participantes, além de irem ao encontro dos dados levantados durante todos os momentos da pesquisa, representam um olhar atento dos jovens para a sua formação integral, bem como para o horizonte da integração curricular.

Também cabe destacar, segundo as próprias falas dos estudantes, o diferencial da oficina, por se constituir em espaço informal de diálogo, trazendo elementos de discussão e análise que eram ainda desconhecidos por parte dos jovens, especificamente no que se refere aos princípios da integração curricular conforme afirmados no PPC dos cursos. Considera-se que o conhecimento desses documentos desenvolvido por meio de estratégias dialógicas mostrou-se importante aos jovens, que reafirmaram essa necessidade no momento da sistematização das reflexões, além de demandarem a construção coletiva dos projetos de curso quando trataram dos espaços de participação.

A oficina formativa teve por objetivo fomentar a participação dos estudantes em espaços de discussão e formação a respeito do currículo integrado, visando à materialização da integração de conhecimentos e sujeitos do currículo e à formação integral, a qual pressupõe o desenvolvimento dos sujeitos em suas diferentes dimensões e a superação de reducionismos formativos. Acredita-se que a atividade possibilitou aos jovens a experiência de formação a respeito dos cursos de EMI, seus propósitos e suas dimensões, bem como a oportunidade de reflexão a respeito das 
suas vivências nos espaços institucionais de participação coletiva a partir dos objetivos formativos propostos para o currículo integrado

\section{Considerações Finais}

Um olhar atento às mais recentes alterações na legislação educacional, com especial enfoque para as alterações realizadas na Lei de Diretrizes e Bases da Educação Nacional (LDB), a Base Nacional Comum Curricular e as atualizações das Diretrizes Curriculares Nacionais para o Ensino Médio e as Diretrizes para a Educação Profissional e Tecnológica, indica que as reformas curriculares, em sua base, demonstram como as políticas educacionais não se separam dos projetos políticos de Estado, chamando a atenção para as finalidades sociais atribuídas à educação e, especificamente, ao Ensino Médio.

Diante do cenário de reformas e de uma regularização cada vez mais acentuada sobre o currículo, é indispensável questionar os encaminhamentos que vêm sendo propostos/ impostos para a Educação Profissional em sua forma integrada.

Por isso, talvez mais do que nunca, análises a respeito da natureza e do histórico desse currículo, bem como as experiências e os sentidos que os seus sujeitos desenvolvem, são relevantes para fundamentar os posicionamentos das instituições e dos atores que o constroem diariamente.

O enfoque dado aos sujeitos do currículo, nesta pesquisa, justificou, portanto, a busca por compreender de que maneira as suas pluralidades integram-se às dimensões plurais do próprio currículo integrado - trabalho, ciência, cultura e tecnologia -, bem como os sentidos que são construídos nesse processo, tomando o conhecimento como estratégia político-pedagógica para a integração. O conhecimento, nesse sentido, foi concebido de forma ampla, ou seja, o processo da instituição conhecer e compreender as identidades dos estudantes bem como esses jovens conhecerem a natureza e os objetivos da formação integrada, a fim de que pudessem vivenciar um protagonismo real nos espaços de participação coletiva.

Quanto à experiência da oficina, não se pode perder de vista que ela se constitui formativa tanto pelos temas que aborda quanto pela oportunidade de participação e construção de conhecimento, de maneira coletiva e dialógica. Os jovens que estão inseridos no currículo integrado precisam compreender os sentidos da integração em suas próprias vidas, nas dimensões da cultura, do trabalho, da ciência e da tecnologia. Para isso, perceber-se como sujeitos ativos do processo formativo, que produzem conhecimentos e são ouvidos e compreendidos a partir de suas identidades e expectativas, representa uma vivência política e pedagógica para a formação integral.

Ainda é necessário enfatizar, destacando-se novamente o caráter coletivo do projeto do currículo integrado, que a oficina precisa ser abordada como uma estratégia metodológica para a materialização desse currículo sem, no entanto, recair em um processo de culpabilização dos estudantes pela falta de compreensão acerca do EMI. Assim como se propõe a oficina formativa para os estudantes, afirma-se que os demais sujeitos do currículo também precisam de formação. $E$, indo mais além, acredita-se que não se trata apenas de uma formação isolada, mas de formação continuada que se estabelece a partir da práxis. 
Para que o currículo integrado seja vivenciado enquanto um projeto ético-político, é imprescindível que as ações, para além das estratégias didáticas e metodológicas, sejam pensadas e desenvolvidas tendo como horizonte os princípios e objetivos emancipatórios do currículo integrado. E, dessa maneira, compreende-se que os sujeitos formam-se a partir da vivência da integração construída no cotidiano do EMI.

Diante das discussões apresentadas, compreende-se que a construção de um currículo integrado é desafiadora e exige de seus sujeitos reflexões acerca de concepções e sentidos historicamente estabelecidos como verdadeiros e inquestionáveis. Tradicionalmente, o sistema escolar formal não desenvolve ações ou projetos integrados e assim, muitos daqueles que, hoje, se inserem no contexto da EPT, no qual se propõe o currículo integrado, não foram formados dessa maneira. Por isso, corrobora-se com a necessidade de uma mudança de postura frente aos conhecimentos, à organização curricular e à participação dos sujeitos que vivenciam o currículo integrado, sempre a partir de um esforço e um projeto coletivos, pautados pelo compromisso ético-político da integração.

\section{Referências}

ANASTASIOU, Lea das Graças Camargos. Estratégias de ensinagem. In: ANASTASIOU, Lea das Graças Camargos; ALVES, Leonir Pessate (orgs.).

Processos de ensinagem na universidade: pressupostos para as estratégias de trabalho em aula. 3. ed. Joinville, SC: Univille, 2004.

ARROYO, Miguel Gonzales. Currículo, território em disputa. 5.ed. Petrópolis, RJ: Vozes, 2013.

ARROYO, Miguel Gonzales. Imagens quebradas: trajetórias e tempos de alunos e mestres. 8. ed. Petrópolis, RJ: Vozes, 2014.

BATISTA, Fátima da Silva. Jovens atores sociais em interlocução com o mundo do trabalho: possíveis mediações são feitas pela escola de ensino médio? 2007. 214f. Dissertação (Mestrado em Educação) - Universidade Estácio de Sá, Rio de Janeiro, 2007. Disponível em:

http://www.estacio.br/mestrado/educacao/completa/tmae/fatima da silva batista.pdf . Acesso em: 21 out. 2021.

BERNARDIM, Márcio Luz; SILVA, Monica Ribeiro da. Juventude, escola e trabalho: sentidos da educação profissional integrada ao ensino médio. Educação em

Revista, n.1, v.32, jan./ mar. 2016. Belo Horizonte: 2016. Disponível em: http://www.scielo.br/scielo.php?pid=S010246982016000100211\&script=sci abstract\&tlng=pt. Acesso em: 21 out. 2021.

BURMESTER, Ana Claudia. Tempos e Espaços Para (Re)Pensar o Currículo com Estudantes do Ensino Médio Integrado. Dissertação (Mestrado em Educação) - ProfEPT IFSC, Florianópolis, 2019. Disponível em: https://repositorio.ifsc.edu.br/bitstream/handle/123456789/1136/dissertacao finalizad a 08 05.pdf?sequence=1\&isAllowed=y. Acesso em: 21 out. 2021. 
CARRANO, Paulo; DAYRELL, Juarez. Juventude e Ensino Médio: quem é este aluno que chega à escola. In: CARRANO, Paulo; DAYRELL, Juarez; MAIA, Carla Linhares (org.). Juventude e ensino médio: sujeitos e currículos em diálogo. Belo Horizonte: UFMG, 2014.

CIAVATTA, Maria. A formação integrada: a escola e o trabalho como lugares de memória e de identidade. In: FRIGOTTO, Gaudêncio; CIAVATTA, Maria; RAMOS, Marise Nogueira. (orgs.). Ensino médio integrado: concepções e contradições. 3.ed. São Paulo: Cortez, 2012

DAYRELL, Juarez. A escola "faz" as juventudes? Reflexões em torno da socialização juvenil. Educação e Sociedade, Campinas, vol. 28, n. 100 - Especial, p. 1105-1128, out. 2007. Disponível em: http://www.scielo.br/pdf/es/v28n100/a2228100. Acesso em: 22 abr. 2020.

FREIRE, Gabriel Gonçalves; GUERRINI, Daniel; DUTRA, Alessandra. O Mestrado Profissional em Ensino e os produtos educacionais: a pesquisa na formação docente. Porto das Letras, v. 2, n.1, 2016. Disponível em: https://sistemas.uft.edu.br/periodicos/index.php/portodasletras/article/view/2658/9381 Acesso em: 30 abr. 2020.

FRIGOTTO, Gaudêncio. Concepções e mudanças no mundo do trabalho e o ensino médio. In: FRIGOTTO, Gaudêncio; CIAVATTA, Maria; RAMOS, Marise Nogueira. (org.). Ensino médio integrado: concepções e contradições. 3.ed. São Paulo: Cortez, 2012.

GOMES, Romeu. Análise e interpretação de dados de pesquisa qualitativa. In: MINAYO, Maria Cecília de Souza (org.). Pesquisa social: teoria, método e criatividade. 25. ed. Petrópolis, RJ: Vozes, 2007.

GUSMÃO, Claudio Alexandre. Educação profissional Técnica de Nível Médio Integrada ao Ensino Médio: a perda do caráter profissionalizante? 2016. 181f. Dissertação (Mestrado em Educação) - Faculdade de Educação da Universidade de Brasília, Brasília, 2016. Disponível em: http://repositorio.unb.br/handle/10482/20249. Acesso em: 28 abr. 2020.

LE BOTERF, Guy. Pesquisa participante: propostas e reflexões metodológicas. In: BRANDÃO, Carlos Roberto (org.). Repensando a pesquisa participante. 3. ed. São Paulo: Brasiliense, 1987.

LECCARDI, Carmen. Por um novo significado do futuro: mudança social, jovens e tempo. Tempo Social, v. 17, n. 2, p. 35 - 57, nov. 2005. Disponível em: https://www.revistas.usp.br/ts/article/view/12470. Acesso em: 21 abr. 2020.

MACHADO, Lucilia. Ensino Médio e técnico com currículos integrados: propostas de ação didática para uma relação não fantasiosa. In: MOLL, Jaqueline. (org.). Educação profissional e tecnológica no Brasil contemporâneo: desafios, tensões e possibilidades. Porto Alegre: Artmed, 2010. 
MARTINS, Francisco André Silva; DAYRELL, Juarez. Juventude e participação: disputas e relações no cotidiano escolar. 2013. Disponível em:

http://observatoriodajuventude.ufmg.br/publication/view/juventude-e-participacaodisputas-e-relacoes-no-cotidiano-escolar/. Acesso em: 30 abr. 2020.

MOURA, Adriana Ferro; LIMA, Maria Gloria. A reinvenção da roda: roda de conversa: um instrumento metodológico possível. Temas em Educação, v.23, n. 1, p. 98 - 106, Piauí, jan. - jun. 2014. Disponível em:

http://www.periodicos.ufpb.br/index.php/rteo/article/view/18338/0. Acesso em: 27 maio 2020.

MOURA, Dante Henrique; LIMA FILHO, Domingos Leite; SILVA, Mônica Ribeiro. Politecnia e formação integrada: confrontos conceituais, projetos políticos e contradições históricas da educação brasileira. Revista Brasileira de Educação, v. 20, n. 63, out./ dez. 2015. Disponível em: http://www.scielo.br/scielo.php?pid=S141324782015000401057\&script=sci abstract\&tlng=pt. Acesso em: 17 dez. 2020.

PINTO, Álvaro Vieira. O conceito de tecnologia. v. 1. Rio de Janeiro: Contraponto, 2005.

RAMOS, Marise Nogueira. Concepção do Ensino Médio Integrado. 2008. Disponível em:

http://forumeja.org.br/go/sites/forumeja.org.br.go/files/concepcao do ensino medio integrado5.pdf. Acesso em: 03 nov. 2020.

RAMOS, Marise Nogueira. Ensino médio integrado: ciência, trabalho e cultura na relação entre educação profissional e educação básica. In: MOLL, Jaqueline. (org.). Educação profissional e tecnológica no Brasil contemporâneo: desafios, tensões e possibilidades. Porto Alegre: Artmed, 2010.

RAMOS, Marise Nogueira. Ensino médio integrado: da conceituação à operacionalização. Cadernos de Pesquisa em Educação, Vitória, a.11, v. 19, n. 39, p.15 - 29, jan./ jun. 2014. Disponível em:

http://periodicos.ufes.br/educacao/article/view/10243. Acesso em: 20 mar. 2020.

SILVA, Adriano Larentes da. Currículo integrado. Florianópolis: IFSC, 2014.

SILVA, Tomaz. Tadeu da. Documentos de identidade: introdução às teorias do currículo. 3.ed. Belo Horizonte: Autêntica, 2015.

WARSCHAUER, Cecília. Rodas e narrativas: caminhos para a autoria de pensamento, para a inclusão e a formação. 2004. Disponível em: http://www.academia.edu/2116274/Rodas e narrativas caminhos para a autoria de pensamento para a inclus $\% \mathrm{C} 3 \% \mathrm{~A} 30$ e a forma\%C3\%A7\%C3\%A3o. Acesso em: 01 dez. 2020.

ZIBAS, Dagmar; FERRETTI, Celso; TARTUCE, Gisela Lobo. Micropolítica escolar e estratégias para o desenvolvimento do protagonismo juvenil. Cadernos de Pesquisa, v. 36, n. 127, p. 51 - 85, jan./ abr. 2006. Disponível em: http://www.scielo.br/pdf/cp/v36n127/a0436127.pdf. Acesso em: 29 abr. 2020. 
Recebido: 28/01/2021

Aprovado: 08/11/2021

Como citar: PASQUALLI, R.; BURMESTER, A. C. Currículo integrado, juventudes e espaços de participação. Educitec - Revista de Estudos e Pesquisas sobre Ensino Tecnológico, v. 7, e165521, 2021.

Contribuição de autoria:

Roberta Pasqualli: Conceituação, administração de projeto, supervisão, análise formal, metodologia, visualização, escrita (rascunho original) e escrita (revisão e edição).

Ana Claudia Burmester: Curadoria de dados, análise formal, investigação, metodologia, validação, visualização, escrita (rascunho original) e escrita (revisão e edição).

Direito autoral: Este artigo está licenciado sob os termos da Licença Creative CommonsAtribuição 4.0 Internacional 